\title{
A Study of The Reasons for Deferral of Voluntary Blood Donors at A Tertiary Care Hospital
}

\author{
Nisha Attri*, Sangita Margam and Anjali Mahajan \\ Dept. of Pathology, Lokmanya Tilak Municipal Medical College \& General Hospital, Sion, Mumbai, India
}

\begin{abstract}
Background: Voluntary blood donation forms the basis of procurement of safe blood from a healthy donor. Donor selection is necessary in addition to the screenings of blood bags for infectious diseases. Deferrals lead to loss of precious blood/components available for transfusion. For preventing this, we should be having knowledge of causes of deferral and their frequency.

Methods: The study was conducted in the blood bank of Lokmanya Tilak Municipal Medical College and General Hospital, Sion, Mumbai, India, from January 2017 to July 2018 to determine the incidence of deferrals. The aim of our study is to know the incidence of donors who were deferred from donating blood and to determine the causes of permanent and temporary deferral.

Result: A total of 21,433 donors were screened. Out of which, 1134 donors were deferred. The total donor deferral rate was $5.29 \%$; the percentages of deferral being $1.62 \%$ for females and $3.67 \%$ for males. The deferral was maximum between $18-40$ years of age.The temporary deferral was more common than permanent deferral; the reasons in males being anemia, low blood pressure and underweight. The reasons documented in females being anemia, menstrual history within one week, followed by underweight. The most common reason in both males and females, for permanent deferral was hypertension.

Conclusion: Donor deferral rate of $5.29 \%$ was found in this study. Females coming forward for blood donation were significantly low. The major causes of deferral were anemia and hypertension.
\end{abstract}

Keywords: : Blood donation, Deferral causes, Door anemia, Donor retrieval.

\section{Introduction}

In current medical practice, a blood transfusion can be a vital life saving procedure. But it requires a safe supply of blood from a healthy donor. Voluntary blood donation forms the basis of procurement of safe blood for patient care across the world and India. For this, donor selection is necessary in addition to the screenings of blood bags for infectious diseases.

However, deferrals lead to loss of precious blood/ components available for transfusion. For preventing this, we should be having knowledge of causes of deferral and their frequency. Statistics of the National AIDS Control Organization (NACO) show that the annual rate of blood donation in India is about 7.4 million units, against the requirement of 10 million units.

A blood bank plays an important role in ensuring the supply of safe blood as and when required. Although it is important to ensure that there is an adequate supply of blood, it is also essential that the blood collection process does not harm either the donor or the recipient. This is achieved by having donor deferral criteria and stringent screening of collected blood for possible transfusion transmissible infections.
The rate and reasons of deferral differs from region to region and centre to centre. A voluntary donor is one who donates without any rewards or compulsion whereas a replacement donor is one who donates blood upon request of specific patient or patient's family. Potential blood donors may not be able to donate for several reasons. A donor who has been deferred can be due to temporary or permanent reasons. A temporarily deferred donor are deferred for a specific time period, but most often these prospective donors are then less likely to return in future for donation thinking they have been deferred for life time. Therefore individual deferred must given proper counselling and education regarding the reason for their deferral and advice them how to rectify the issue before the next visit.

Few studies conducted in India in the past have provided different reasons for deferral of whole blood donors, highlighting different demographic profile in different parts of the country. The aim of our study is to know the demographic profile of donors who were deferred from donating blood and to determine the causes of permanent and temporary deferral.

The study was conducted in the blood bank of Lokmanya Tilak Municipal Medical College and General Hospital, 
Sion, Mumbai, India, from January 2017 to July 2018 to determine the incidence of deferrals.

\section{Materials and Methods}

A study carried out in the blood bank of a tertiary care hospital. The study includes deferred donors from indoor voluntary donations and outdoor camps conducted by blood bank during the period January 2017 to July 2018. Data was collected from the records maintained in the centre. A donor questionnaire was used for screening. Details of all those who were deferred were recorded in the deferral register. The deferred donors were analyzed on the basis of sex, cause of deferral. All the donors were screened properly to ensure the blood drawn is safe for transfusion.

The voluntary donors, of both outdoor camps and indoor hospital categories, were evaluated on the basis of elaborate clinical history including age, high risk behaviour with multiple sexual partners, history of jaundice, tattoos, history of intake of alcohol within 24 hours, history of any medication intake, vaccination history etc. For women additional history of menstrual cycle within one week, any abortions etc. was taken. Physical examination, Hemoglobin estimation, blood pressure, and temperature recording were performed. W.H.O. guidelines were used for deferral of blood donors. Data was recorded and maintained by the blood bank in donor register. Hemoglobin was measured by Hemocue and Copper sulphate method. Blood samples of these donors were screened for HBsAg by HBsAg ELISA Test kit, anti HCV by 3rd Generation Anti-HCV ELISA test, anti-HIV by HIV1/2 ELISA, Malaria by Pf/Pv ELISA, and syphilis by RPR card test. The criteria for selection were age limit of 18-60 years, minimum weight of $45 \mathrm{~kg}$, pulse rate $60-100 \mathrm{~b} / \mathrm{m}$, temperature $37.2-37.7^{\circ}$ Celsius, systolic B.P between 100-160 mmHg, diastolic B.P between 50$100 \mathrm{~mm} \mathrm{Hg}$ and minimum hemoglobin of $12.5 \mathrm{gm} \%$. Donors not fulfilling the selection criteria were deferred. Donors with past history of typhoid or malaria or tooth extraction within past 6 months, past history of high risk sexual behaviour, tattooing, drug intake within 72 hours, alcohol intake within 24 hours, history of intravenous drug abuse, diabetes, patients with hypertension were deferred. Patients with hemoglobin less than 12.5 were temporarily deferred as well as females with history of abortion within 1 month. Temporarily deferred patients were asked to come back after a suitable period of time.

\section{Result}

A total of 21,433 donors were registered for voluntary donation from $1^{\text {st }}$ January 2017 to $31^{\text {st }}$ July 2018, out of which 15, 543 were males and 5890 were females. Total 1134 donors were deferred; out of which; 347 were females and 787 were males. As such, the total donor deferral rate was $5.29 \%$; the percentages of deferral being $1.62 \%$ for females and $3.67 \%$ for males (Table- 1). A large proportion of the deferred donors were aged between 18 years and 30 years $(52 \%)$ (Table- 2$)$. Analysis of the deferrals showed that the temporary deferral was more common than permanent deferral. The reasons in males being anemia, low blood pressure, underweight and alcohol intake within last 24 hours in that order. The reasons documented in females being anemia, menstrual history within one week, followed by underweight. The reasons in both males and females, for permanent deferral were hypertension, diabetes and high risk behaviour with multiple partners (Table- 3,4).

\section{Discussion}

Total of 21, 433 donors who came forward for blood donation, of which about 1134 cases $; 5.29 \%$ were deferred due various reasons. Several studies have reported a similar deferral rate $(5.20 \%)$ by Unnikrishnan et al ${ }^{(1)},(6 \%)$ by Sundar et $a l^{(2)}$, and (5.6\%) by Rabeya et al ${ }^{(3)}$. Some studies have even had a higher deferral rate of (16.4\%) Chaudhary et al ${ }^{(4)},(35.6 \%)$ Charles et al ${ }^{(5)}$. Even though deferral rate were found to be similar, the major reasons for deferral varies reflecting disparity in socioeconomic status. The deferral rate differs from region to region and centre to centre. These varied differences in the rate could be due to different donor selection criteria. Adherence to the screening criteria for blood donors will help keep the proportion of deferrals to an acceptable minimum. Male constituted around $73 \%$ of the donors who came to donate blood. The number of females volunteering for the donation were as few as $27 \%$ only. Present study showed that female donors deferred were $1.62 \%$ as compared to male donors which were $3.67 \%$. This is because of prevalence of false belief that females cannot donate. Although, due to physiological factors, women may be more prone to conditions such as anemia, but a proper predonation counselling will help decide whether one should or shouldn't donate. Present study showed that female donors were deferred more frequently than male donors which might be due to the wide prevalence of anemia and underweight factors in female donors.

Causes of deferral were many and were broadly classified as temporary and permanent. More number of deferrals were temporary constituting about $81.30 \%$ and permanent deferral, about $18.69 \%$. This was similar to the study of Sunder et al (2) (Figure-1)

The most common cause among temporary deferral was anemia $(32.53 \%)$ as compared to Halperin, et al. ${ }^{(6)}$ which showed low hemoglobin as the most common cause in $46 \%$ of the temporary deferral. Those with anemia have to be referred for further evaluation and treatment. Studies by 
Newman et al show that by lowering hemoglobin standard levels and offering iron treatment for pre-menopausal woman, one could increase female eligibility ${ }^{(7)}$.

The other causes of temporary deferral included alcohol intake, underweight, drug intake, history of jaundice, malaria or typhoid, tooth extraction within 6 months, menstrual history within one week in females. Donors should be informed regarding the common causes of temporary deferrals like smoking and alcohol prior to blood donation, age limit, menstruation, breastfeeding women, drugs that cannot be consumed prior to donation etc.. This helps donors pre-screen themselves.

The major problem faced is that, most of the deferred donors are less likely to return in future for donation thinking they have been deferred for life time. Zou et al have reported potential donor loss after a deferral ${ }^{(8)}$. Therefore all deferred individuals must be informed about the cause and period of deferral and proper counselling must be done to help them overcome the problem so that these donors can be recruited back to donors' pool.

In our study $18.69 \%$ of donors were deferred for permanent reasons. On comparison in other studies, Custer, et al. (9) reported a permanent deferral rate of $10.6 \%$ and Arslan ${ }^{(10)}$ reported a rate of $10 \%$. The leading cause for permanent deferral in our study was hypertension, overage and diabetes followed by high risk behaviour among donors with multiple sexual partners. This correlated with the study done by Bahadur et al. ${ }^{(11)}$, who stated hypertension as the commonest cause of permanent deferral in their studies (Figure-2). The probable reason could be sight of blood, first time blood donation, fear of phlebotomy, white coat hypertension, stress and exercise. Hypertension often goes undetected and is mostly the incidental finding while screening donors.

Similar to the findings in a study done by Hinal Gajjar et al. a large proportion of the deferred donors were aged between 18 years and 30 years $(52 \%)$ which also incidentally is the major age group to which most of the voluntary blood donors belong to. This points towards the low micronutrient levels in the youth, which when improved will significantly reduce deferrals due to temporary reasons like anemia. ${ }^{(12)}$

Therefore, more number of awareness programs regarding importance of blood donation has to be conducted to increase the number of voluntary donors. In the study by Shahshahani et al, free pre-donation medical checkups, free blood investigations could also help motivate people to donate blood ${ }^{(13)}$ and help them clear all misconceptions. Donors must be assured that blood donation is safe and there is no risk of contracting any infection. Moreover, body replaces the lost fluids within 24 hours of blood donation and the lost red blood cells in a few weeks.

Table 1; Deferral percentage $\&$ demographic profile of the donors.

\begin{tabular}{|c|c|c|c|}
\hline Sex of the donor & Registered donors & Deferred donors & $\begin{array}{c}\text { Percentage of deferrals of } \\
\text { total registered donors }\end{array}$ \\
\hline Male & 15543 & 787 & $3.67 \%$ \\
\hline Female & 5890 & 347 & $1.62 \%$ \\
\hline Total & $\mathbf{2 1 4 3 3}$ & $\mathbf{1 1 3 4}$ & $\mathbf{5 . 2 9 \%}$ \\
\hline
\end{tabular}

Table 2 ; Age wise distribution of deferred blood donors.

\begin{tabular}{|c|c|c|c|c|c|}
\hline \multicolumn{3}{|c|}{ Male(787) } & \multicolumn{3}{|c|}{ Female (347) } \\
\hline Age (yrs) & No. & Percent & Age(yrs) & No. & Percent \\
\hline$<\mathbf{1 8}$ & 20 & $2.54 \%$ & $<\mathbf{1 8}$ & 4 & $1.15 \%$ \\
\hline $\mathbf{1 8 - 3 0}$ & 377 & $47.90 \%$ & $\mathbf{1 8 - 3 0}$ & 207 & $59.65 \%$ \\
\hline $\mathbf{3 1 - 4 0}$ & 182 & $23.12 \%$ & $\mathbf{3 1 - 4 0}$ & 68 & $19.59 \%$ \\
\hline $\mathbf{4 1 - 5 0}$ & 128 & $16.26 \%$ & $\mathbf{4 1 - 5 0}$ & 56 & $16.13 \%$ \\
\hline $\mathbf{5 1 - 6 0}$ & 67 & $8.51 \%$ & $\mathbf{5 1 - 6 0}$ & 8 & $2.30 \%$ \\
\hline$>\mathbf{6 0}$ & 13 & $1.65 \%$ & $>\mathbf{6 0}$ & 4 & $1.15 \%$ \\
\hline Total & 787 & $100 \%$ & Total & 347 & $100 \%$ \\
\hline
\end{tabular}


Table 3; Causes of Temporary deferrals with their relative proportions.

\begin{tabular}{|c|c|c|c|c|c|}
\hline Reason for deferral & Male & Female & Total & $\begin{array}{c}\text { Percentage of } \\
\text { temporary deferrals }\end{array}$ & $\begin{array}{c}\text { Percentage of total } \\
\text { deferrals }\end{array}$ \\
\hline Low Hemoglobin $(<12.5)$ & 148 & 152 & 300 & $32.53 \%$ & $26.45 \%$ \\
\hline Underweight & 77 & 42 & 119 & $12.90 \%$ & $10.49 \%$ \\
\hline Underage & 20 & 4 & 24 & $2.60 \%$ & $2.11 \%$ \\
\hline Low B.P & 84 & 36 & 120 & $13.01 \%$ & $10.58 \%$ \\
\hline Medication & 56 & 15 & 71 & $7.70 \%$ & $6.26 \%$ \\
\hline Alcohol intake $<24$ hours & 67 & - & 67 & $7.26 \%$ & $5.90 \%$ \\
\hline Menstrual history within 1 week & - & 45 & 45 & $4.88 \%$ & $3.96 \%$ \\
\hline Sleep deprivation $<4$ hours & 16 & 3 & 19 & $2.06 \%$ & $1.67 \%$ \\
\hline Tattooing within 1 year & 23 & 7 & 30 & $3.25 \%$ & $2.64 \%$ \\
\hline Ear piercing within 6 months & 2 & 3 & 5 & $0.54 \%$ & $0.44 \%$ \\
\hline Jaundice or typhoid within 6 months & 27 & 2 & 29 & $3.14 \%$ & $2.55 \%$ \\
\hline Tooth extraction within 6 months & 13 & 1 & 14 & $1.51 \%$ & $1.23 \%$ \\
\hline Lactation or abortion within 6 months & - & 1 & 1 & $0.10 \%$ & $0.08 \%$ \\
\hline Vaccinations within 6 months & 9 & - & 9 & $0.97 \%$ & $0.79 \%$ \\
\hline Infection & 4 & 2 & 6 & $0.65 \%$ & $0.52 \%$ \\
\hline Fever & 13 & 5 & 18 & $1.95 \%$ & $1.58 \%$ \\
\hline Diarrhoea & 5 & - & 5 & $0.54 \%$ & $0.44 \%$ \\
\hline Recent surgery & 11 & 2 & 13 & $1.40 \%$ & $1.14 \%$ \\
\hline Recent donor within 3 months & 23 & 4 & 27 & $2.92 \%$ & $2.38 \%$ \\
\hline Total & 598 & 324 & 922 & $100 \%$ & $81.30 \%$ \\
\hline
\end{tabular}

Table 4 ; Causes of Permanent deferrals with their relative proportions.

\begin{tabular}{|l|l|l|l|l|l|}
\hline $\begin{array}{l}\text { Reason for } \\
\text { deferral }\end{array}$ & Male & Female & Total & $\begin{array}{l}\text { Percentage of } \\
\text { permanent deferral }\end{array}$ & $\begin{array}{l}\text { Percentage of } \\
\text { total deferral }\end{array}$ \\
\hline High B.P & 142 & 11 & 153 & $72.16 \%$ & $13.49 \%$ \\
\hline Diabetes & 11 & 2 & 13 & $6.13 \%$ & $1.14 \%$ \\
\hline Thyroid disorder & 2 & 3 & 5 & $2.35 \%$ & $0.44 \%$ \\
\hline Heart disease & 3 & 1 & 4 & $1.88 \%$ & $0.35 \%$ \\
\hline Kidney disease & 1 & - & 1 & $0.47 \%$ & $0.08 \%$ \\
\hline Liver disease & 2 & - & 2 & $0.94 \%$ & $0.17 \%$ \\
\hline Epilepsy & 4 & - & 4 & $1.88 \%$ & $0.35 \%$ \\
\hline Asthma & 5 & 2 & 7 & $3.30 \%$ & $0.61 \%$ \\
\hline Overage & 13 & 4 & 17 & $8.01 \%$ & $1.49 \%$ \\
\hline $\begin{array}{l}\text { High risk } \\
\text { behaviour }\end{array}$ & 6 & - & 6 & $2.83 \%$ & $0.52 \%$ \\
\hline Total & $\mathbf{1 8 9}$ & $\mathbf{2 3}$ & $\mathbf{2 1 2}$ & $\mathbf{1 0 0 \%}$ & $\mathbf{1 8 . 6 9 \%}$ \\
\hline
\end{tabular}




\section{Type of deferrals}

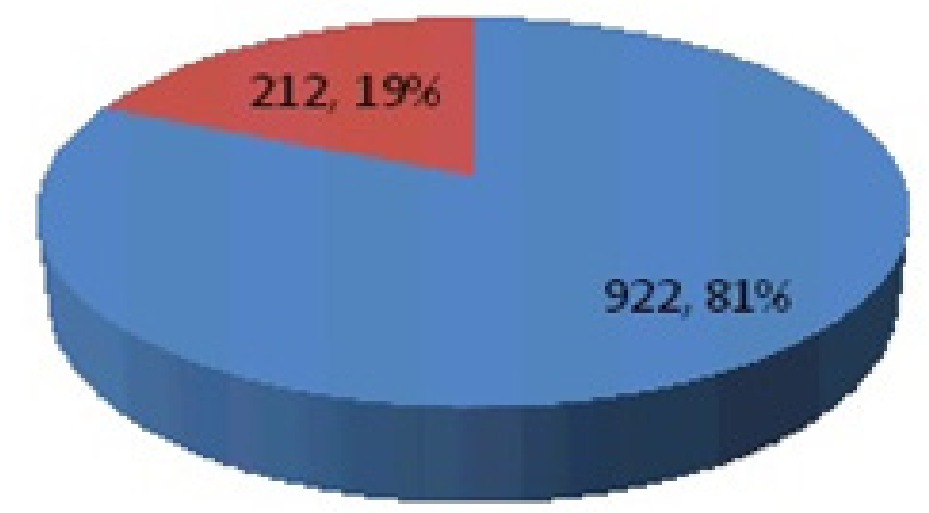

Temporary

Permanent

Temporary deferral was more common than permanent deferral. Temporary constituted $81 \%$ and permanent constituted $19 \%$ of the total deferrals. This was similar to the study of Sunder et al.(2).

Fig. 1: Distribution of deferrals according to temporary or permanent deferal.

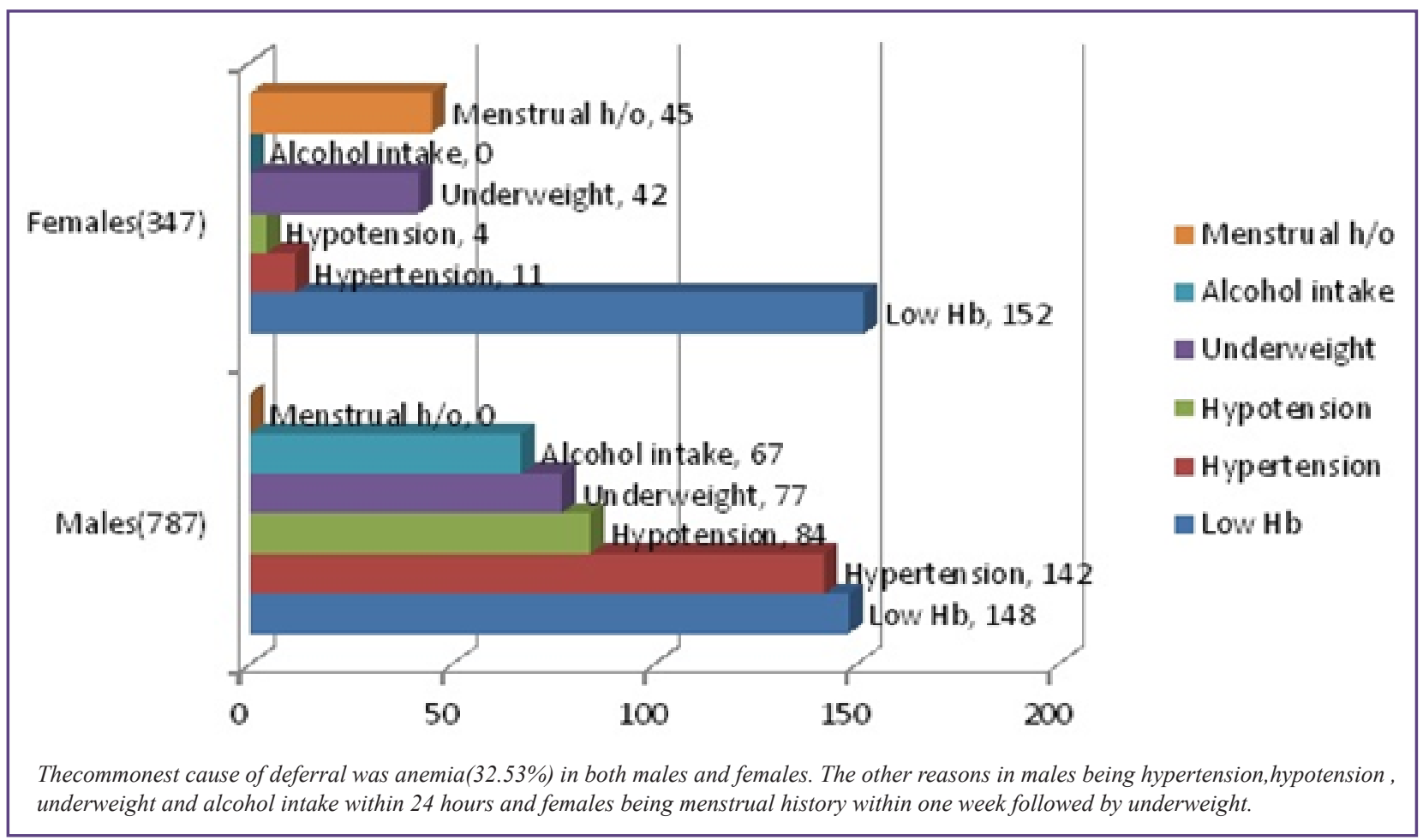

Fig. 2: Top reasons for deferral in males \& females. 


\section{Conclusion}

Our study showed that although donor deferral rates were very much similar in different populations, the reasons for deferral differ, reflecting difference in socioeconomic status and environment. However, some studies showed that different deferral rate could be due to different donor selection criteria. Analysis of deferral patterns may help medical personnel and doctors to be more focused in donor screening, especially of those which are having higher occurrence. The Leading causes of permanent and temporary deferrals were hypertension and anemia respectively. Temporarily deferred donors require proper follow up and management so that it does not lead to a diminished supply of future donors. A more pro-active role in decreasing anemia needs to be taken by providing quality nutrition to all and also by undertaking more educational programs towards elimination of transfusion transmitted infections.

Temporarily deferred individuals must be informed about the reason as well as the period of deferral. They must be encouraged and given counselling to help them overcome the problem before the next visit, thus we could reduce huge percent of temporary deferral. Educating the people in the community a week prior to the scheduled camp regarding some of common causes of deferrals like smoking and alcohol prior to visit, age limit, menstruation, breastfeeding women etc. may help pre- screen them self and avoid unnecessary deferrals.

Finally, to improve the safety of blood and blood products and to decrease loss of blood/ components, four steps must be included: (1) detail history based on WHO guidelines, (2) physical examination, (3) laboratory tests including ELISA for anti HIV, anti $\mathrm{HCV}$ and HBsAg and other tests for malaria and syphilis and (4) public awareness, educational and motivational programs.

So to conclude, it is important to determine the proportion and causes of blood donor deferral for the safety of blood transfusion and also to guide the donor recruitment efforts to prevent loss of precious blood/components at local, national and international levels.

\section{Acknowledgements}

I hereby acknowledge the entire staff of Blood Bank, L.T.M.M.C. Sion, for cooperating with me in the data collection and encouraging me throughout the process.

\section{References}

1. Unnikrishnan B, Rao P, Kumar N, Ganti S, Prasad R, Amarnath A, Reshmi B, Kaur V, Kesharwani P, Seetha M, Nautiyal A, Goel P, Aggarwal A. Profile of blood donors and reasons for deferral in coastal South India. AMJ 2011; 4 (7): 379-385.

2. Sundar P, Sangeetha SK, Seema DM, Marimuthu P, Shivanna N. Pre-donation deferral of blood donors in South Indian setup: An analysis. Asian J Transfusion Sc 2010; 4(2):112-5.

3. Rabeya Y, Rapiaah M, Rosline H, Ahmed SA, Zaidah WA, Roshan TM. Blood pre-donation deferrals-a teaching hospital experience. Southeast Asian J Trop Med Public Health 2008; 39(3):571-4.

4. Chaudhary RK, Gupta D, Gupta RK. Analysis of donordeferral pattern in a voluntary blood donor population. Transfus Med 1995; 5:209-12.

5. Charles KS, Hughes P, Gadd R, Bodkyn CJ, Rodriguez M. Evaluation of blood donor deferral causes in the Trinidad and Tobago National Blood Transfusion Service. Transfus Med 2010; 20:11-4.

6. Halperin D, Baetens J, Newman B. The effect of short-term, temporary deferral on future blood donation. Transfusion 1998; 38: 181-183.

7. Newman BH. Adjusting our management of female blood donors: the key to an adequate blood supply. Transfusion 2004; 44:591-6.

8. Zou S, Masavi F, Noyary EP, Rios JA, Trouern-Trend J, Fang CT. Donor deferral and resulting donor loss at the American Red Cross Blood Services,2001 through 2006. Transfusion 2008; 48: 2531-9.

9. Custer B, Johnson ES, Sullivan SD, Hazlet TK, Ramsey SD, Hirschler NV, et al. Quantifying losses to the donated blood supply due to donor deferral and miscollection. Transfusion 2004; 44:1417-26

10. Arslan $\mathrm{O}$. Whole blood donor deferral rate and characteristics of the Turkish population. Transfus Med 2007; 17: 379-383.

11. Bahadur S, Jain S, Goel RK, Pahuja S, Jain M. Analysis of blood donor deferral characteristics in Delhi, India. Southeast Asian J Trop Med Public Health 2009; 40:1087-91.

12. Gajjar Hinal, Shah FR, Shah NR, Shah CK. Whole blood donor deferral analysis at general hospital blood bank-A retrospective study.NHL Journal of Medical Sciences. July 2014; 3(2):72-76

13. Shahshahani HJ, Yavari MT, Attar M, Ahmadiyeh MH. Knowledge, attitude and practice study about blood donation in the urban population of Yazd, Iran. Transfus Med 2006; $16: 403-9$

*Corresponding author:

Dr. Nisha Attri, C/O Dr. N.S. Attri, Professor, Botany Dept., Punjabi University Patiala, Punjab-147002. INDIA

Phone: $+919819458676,9872743771$

Email: nisha.attri4@gmail.com

Financial or other Competing Interests: None. 